\title{
Insurance and the Institutional Economics of Financial Intermediation
}

\author{
by Göran Skogh*
}

\section{Introduction}

This article integrates insurance into the institutional theory to financial intermediation first discussed by Benston and Smith (1976) and by Leland and Pyle (1977). Heretofore, the theory has been applied mainly to banks. ${ }^{1}$ We generalize the approach and show that it provides a fruitful framework for the study of the insurance industry as well. ${ }^{2}$

In the next section, we present the institutional approach. In Section 3, we model collateral, a guarantee, and an insurance policy. Two traders faced with a risky project contract on liability at a loss. One of the traders controls the risk and is therefore made strictly liable for losses. The amount collectable at a loss is limited, however, which results in less than optimal care. It is shown that collateral, defined as an asset deposited to secure the payment, may increase the care taken and thus the value of the risky project. A guaranteess, that is a contract by which the risk is transfered to an external risk-carrier, a guarantor, may also increase the care taken. The guarantor is assumed to have a relation to the liable party that enables the guarantor to collect more from the liable than others can. The guarantor is also assumed to be well informed about the risky activity and able to influence the liable partly by effectively compensating the liable party for various care levels. We then present an insurance contract that is identical to the guarantee. Insurance is here defined to mean

\footnotetext{
" Associate Professor at the Department of Economics at the University of Lund. Financial support from the Nordic Economic Research Council and Försäkringsbolaget Pensionsgaranti (FPG) is gratefully acknowledged. Thanks are due to David Cummins, Peter Högfeldt, Lars Hörngren, AnneMarie Pålsson, Clifford Smith, Charles Stuart, and Staffan Viotti for comments on earlier versions of the article.

1 E. g. Stiglitz and Weiss (1981), Diamond (1984), Diamond and Dybvig (1986) and Fama (1990). Smith and Warner (1979) and Mayers and Smith (1981, 1982, 1987), and Main (1982, 1983) compare insurance with other forms of financial intermediation. They argue that risk-aversion alone cannot explain the corporate demand for insurance. They suggest that the comparative advantage of the insurance industry is in claims and administration services and in assistance on safety and maintenance projects. Skogh (1989a) argues that contractors' transaction costs may be a rationale for insurance. Mian and Smith (1989) study the management of trade credits, the demand for credit, factoring, and credit insurance. Goldberg (1988) treats collateral, guarantees, and insurance as alternatives in a discussion of accountants' liability.

2 The traditional theory of insurance does not give much guidance on these matters - it explains why risk-averse individuals demand diversification, but it has little to say about the institutions in financial markets or about the details of insurance contracts.
} 
the trade of risk by an insurance contract. The insurance contract is a contract with a primium that is fixed ex ante and that makes the insurer the residual claimant and thus the riskcarrier. ${ }^{3}$ In section 4 , we argue that the differences between guarantors (usually banks) and insurers are due to the type of risk (e.g. insolvency, fire, transport or third party liability) and in the customers in which they specialize. ${ }^{4}$ Section 5 concludes.

\section{The institutional approach to financial intermediation}

The institutional approach to financial intermediation presumes the existence of transactions costs (Benston and Smith, 1976). Namely, if no transaction costs were present, borrowers and lenders could transact directly and avoid the costs of intermediation. Leland and Pyle (1977) distinguish between direct transaction costs (costs of identifying lenders and borrowers and of administering the transaction of financial assets) and costs due to asymmetric information. They argue that direct transaction costs may have an impact on intermediation, but that the magnitude of such costs appears insufficient to explain intermediation. They suggest that informational asymmetries are the prime reason why intermediaries exist.

Leland and Pyle demonstrate the importance of informational asymmetries in a model of capital structure and financial equilibrium in which entrepreneurs seek to finance projects, the true qualities of which are known only to entrepreneurs. An entrepreneur's willingness to invest own funds in the project serves as a signal of project quality (Spence, 1974). As a consequence, the market value of the firm increases with the share of the firm held by the entrepreneur. ${ }^{5}$

Leland and Pyle also suggest that, in a world of asymmetric information and economies of scale, one might expect to observe organizations that gather and sell information. However, the properties of information may make it difficult for firms to profit from obtaining and selling information directly to investors or creditors. One reason is that some information is transaction-specific and hence is not easily traded (Williamson, 1979). For instance, the creditor in the Leland and Pyle example may have a long-term relation (repeated dealings) with the entrepreneur, which gives the creditor a comparative advantage in supervising the entrepreneur - an advantage not easily transfered to others. Another reason is that information is a public good; a firm selling information may therefore not be able to appropriate enough of its value to cover the costs of obtaining it. Reliability of the seller is a third obstacle to direct sales of information. Specifically, it may be difficult for potential buyers to distinguish good information from bad. This is the problem of Akerlof (1970); under it, the price of information should reflect average quality, and firms that expend resources to collect information may end up with losses.

${ }^{3}$ In the pooling-of-risk theory of insurance, the word insurance is used to mean trade of a risk to facilitate risk-sharing and diversification. Our risk-shifting contract need not include diversification.

${ }^{4}$ The analysis is limited to risk-bearing, although most financial intermediaries produce other services as well.

5 Informational asymmetries thus explain why the value of a firm varies with the debt-equity ratio. This is in contrast with the result of Modigliani and Miller (1958), who showed that the financial structure of a firm has no impact on the firm's value, given a capital market without direct transaction costs or asymmetric information. 
These informational obstacles may be overcome if the information-gathering firm becomes an intermediary, using its specialized information to choose the assets it holds. The problems of transaction specificity, appropriability, and reliability are solved to the extent the firm's information is captured indirectly by the return it earns on its portfolio.

\section{Collateral, guarantee, and insurance}

\subsection{The setting}

We argue that the institutional approach summarized above can be applied to traders in general and not only to debtors and creditors. The approach can be applied to any project where risks are transfered to external risk-carriers with specific information about the risks in question. The differences between banks, guarantors, and insurers in the institutional approach here are due to the type of risks and customers in which they specialize.

To see this, consider a situation in which two traders, $A$ and $B$, are to contract on a risky project that is expected to be mutually bencficial. The parties are concerned about liabilities given a potential loss. This problem is of quite general nature. We may think, for instance, of an investment in which $\mathrm{A}$ is the entrepreneur and $\mathrm{B}$ is a creditor. Alternatively, we may think of sharecropping, where $A$ is a tenant farmer and $B$ a landowner. Yet a third possibility is that $A$ produces and markets a dangerous good to $B$, who is a buyer. In this section, we couch the narrative in the dingerous-good case.

We assume that the parties are risk-neutral. ${ }^{6}$ The assets that can be collected at a loss are assumed limited, however, so there is a limit to potential liability. To eliminate intertemporal financial problems other than the ex ante, ex post distinction, we assume there is only one period. The atemporal financial problem analyzed arises because of risk, and because the assets of the liable party may not suffice to cover a loss.

The dangerous good provides the buyer with a value that is given and known ex ante (Y). To obtain the good, B pays an amount $\mathrm{R}$ to $\mathrm{A}$. The riskiness of the project is represented by a potential loss that would arise, say, if the good explodes. The size of the loss $(\mathrm{L})$ is also known, constant, and quantifiable. The loss is borne by the parties in non-negative shares $s^{A}$ and $s^{B}$, where $s^{A}+s^{B}=1$. If $A$ is fully liable for the loss, $s^{A}=1$ and $s^{B}=0$, if they share the loss equally, $s^{A}=s^{B}=1 / 2$, etc.

There are only two states of the world: loss or no loss. The probability of a loss is $p$ and the probability of no loss is $1-p$. The probability of a loss is influenced by a control measure $(x)$ taken by $A$. The control may be the number of safety checks made before delivery of the good. The function $p(\cdot)$ reflects the influence of $x$ on $p$ and is decreasing, convex, and appropriately differentiable. The control has a constant marginal cost, $w$.

Under these assumptions, the net values of the project to $A$ and $B$ are, respectively,

$$
\begin{aligned}
& N V^{A}=R-s^{A} p(x) L-w x, \\
& N V^{B}=Y-R-s^{B} p(x) L .
\end{aligned}
$$

The total profit of the project is

$$
N V=N V^{A}+N V^{B}=Y-p(x) L-x w .
$$

6 The assumption of risk-neutrality simplifies the analysis and emphasizes the difference between the current theory and the traditional approach to insurance. Later, we discuss the impact of risk-aversion. 
Because $N V$ depends on the expected loss, $p(x) L$, and because the costly effort, $x w$, is controlled by $A$, the two traders may contract on the level of the control. We assume that there exists an interval of values of the control, $\left(x^{f}, x^{h}\right)$, such that $N V>0$. For controls in this interval, it is possible to write a mutually beneficial contract. The sharing of $N V$ is determined by the price $R$ and by the liability share $s^{A}$.

\subsection{The first best outcome}

Assume for the moment that both $A$ and $B$ are fully informed about the shape of $p(\cdot) L$ and that they are able to contract without any transaction costs. Assume also that the collectable assets of $A$ and $B$ are larger than the potential loss $L$ so there is no problem of limited liability.

The efficient outcome maximizes (3). The optimal control, denoted $x^{*}$, satisfies the first-order condition.

$$
w=-p_{x} L .
$$

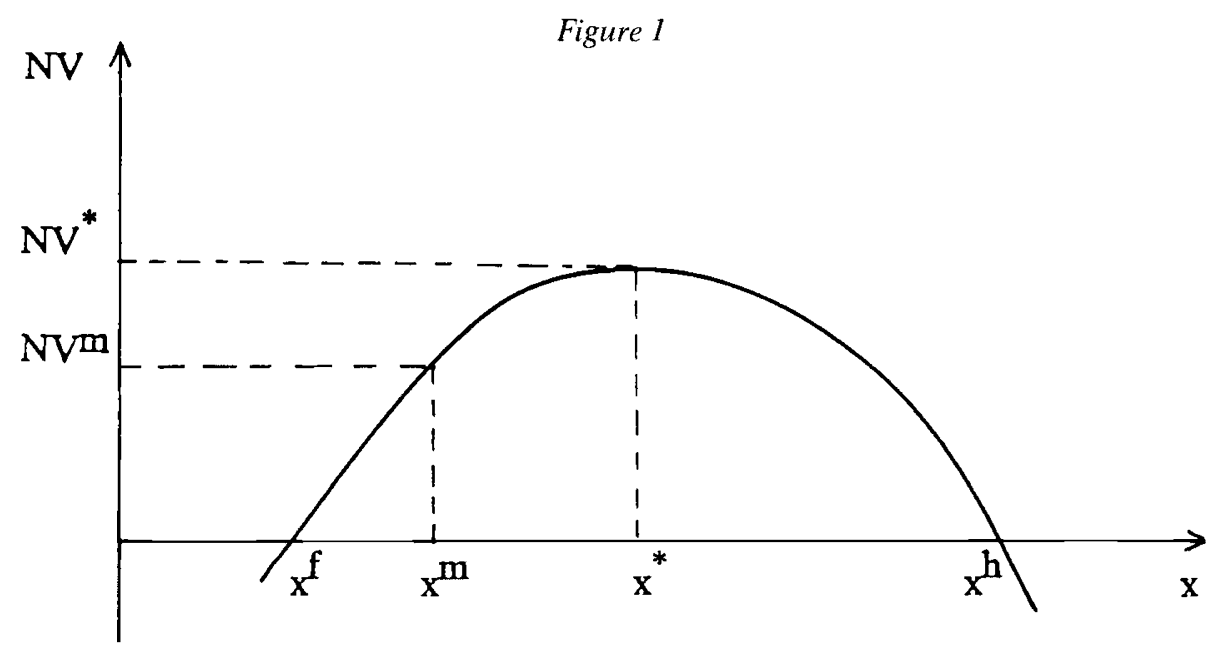

Profit-maximizing traders agree on this control level, as is illustrated in figure 1 . The contract specifies that $x^{*}$ is to be undertaken by $A$. The sharing of the maximal value of $N V$, denoted $N V^{*}$, is settled by the ex ante payment of $R$, and by $s^{A}$, if the loss occurs ex post.

\subsection{Asymmetric information}

We now drop the assumption that both $A$ and $B$ are equally and fully informed about the function $p(\cdot) L$. A alone knows $p(\cdot) L$ and can observe the care taken. $B$, as well as an external enforcer (the courts), can only observe the outcome ex post. We assume that a principal-agent problem arises because the correlation between the control and the outcome is imperfect due to the stochastic nature of the loss. 
The potential inefficiency from this informational asymmetry can be eliminated by making $A$ strictly liability for the loss $\left(s^{A}=1\right)$. In this case, $A$ will minimize

$$
p(x) L+x w
$$

which has the (first-best) first-order condition (4). The level of care taken would then be optimal. ${ }^{7}$ The sharing of $N V^{*}$ would be determined only by the price, $R$. If $A$ were not fully liable $\left(s^{A}<1\right)$, it is easy to see that $A$ would have an insufficient incentive to be careful, and hence $x<x^{*}$.

Thus asymmetric information per se does not exclude efficient control. Strict liability is a requirement for efficiency in this case.

\subsection{Limited collectable assets}

An inefficiency arises, however, when liability is limited or the claim cannot be collected. Denote the maximum amount that $B$ can collect by $M^{B}$, and assume that $M^{B}<L$. If $A$ is strictly liable, $A$ will minimize

$$
p(x) M^{B}+x w,
$$

instead of (5), and the level of care will satisfy

$$
w=-p_{x} M^{B} \text {. }
$$

The level of care that minimizes (5') is denoted $x^{m}$, where it follows easily that $x^{m}<x^{*}$ because $p_{x}(\cdot)$ is decreasing and $M^{B}<L$. The net value of the project is $N V^{m}<N V^{*}$. That is, limited collectable assets results in less than the optimal level of care. If the collectable amount is small relative to the potential loss, the resulting care $\left(x^{m}\right)$ may be smaller than $x^{f}$, so that $N V^{m}<0$ (see figure 1). That is, limited collectability may result in no contract at all.

\subsection{Collateral}

The collectable amount is usually less than the value of all assets owned by the liable party. The amount depends, among other things, on competing claims. Other claims may have a higher legal priority. The expected collectable amount also depends on costs of collecting claims. These costs may be high, for instance, if $A$ and $B$ are strangers that do not expect to trade with each other again; in such cases, $A$ would have no incentive to compensate $B$ ex post for a loss. The level of legally enforceable liability may also be unclear and the liable party may be hard to find. Indeed, $A$ may sometimes be able to avoid paying damages $\left(M^{B}=0\right)$ even if $A$ has substantial assets.

The parties may therefore end up with a project of low value, or with no contract and hence no project at all. A way out of the dilemma may be for $A$ to offer collateral, that is, an asset reserved to ensure payment. "Collateral" in this sense should be interpreted broadly. For instance, a home mortgage effectively provides collateral. The purpose of collateral is to increase the expected collectable amount. ${ }^{8}$ We see easily from (4') that collateral that increases $M^{B}$ also raises care $(x)$ and hence the value of the project. If the collectable amount is increased to $L$, the loss will be fully compensated and the control will be optimal. ch. 3).

7 This result is well established in the economics of tort law and product liability (Shavell 1987,

${ }^{8}$ Collateral may not only increase the collectable amount but also the probability that a given amount can be collected. However, as we assume risk-neutral traders, only the expected amount collected matters here. 


\subsection{Guarantee}

A guarantee is a contract that transfers a risk to an external risk-carrier known as a guarantor $(G)$. Contracts often require guarantees. This section comparcs a guarantee with collateral, and shows that a guarantee can increase the value of a contract in much the same way as collateral does.

One reason why a guarantee may increase the value of a project is that $G$ may be able to collect more from $A$ than $B$ (the victim) can. For instance, $G$ may be specialized in claims collection. $G$ may also be able to collect more from $A$ if $G$ has a long-term relation to $A$ and $B$ does not. Assume, for instance, that $A$ and $B$ do not trade repeatedly. $A$ would then have no incentive to compensate $B$ voluntarily, which can make $M^{B}$ small. $G$, on the other hand, may be able to extract more form $A$ because $G$ trades repeatedly with $A$.

One form of guarantee-contract stipulates that $G$ fully compensates $B$ at a loss, while $G$ collects $M^{G}$ from $A .{ }^{9}$ We assume that $G$ is credible and has sufficient funds to cover the loss. We exclude the possibility that the guarantor collects more than $L$. The price of the guarantee is $I$. Assume that $A$ pays for the guarantee. ${ }^{10}$ In this case, the net values of the three involved parties, including $G$ 's net value, $N V^{G}$, are:

$$
\begin{aligned}
& N V^{A}=R-p(x) M^{G}-w x-I, \\
& \mathrm{~N} V^{\mathrm{B}}=\mathrm{Y}-\mathrm{R}, \\
& N V^{G}=I-p(x)\left(L-M^{G}\right) .
\end{aligned}
$$

The total net value of the project, $N V=N V^{A}+N V^{B}+N V^{G}$ is the same as (3).

To be mutually beneficial, the guarantee must increase the value of the project. As we assume risk-neutrality, this can only occur if the guarantee increases the control $x$, which will be the case if $M^{G}>M^{B}$. If the guarantor can collect the whole loss $\left(M^{G}=L\right)$ the control will be optimal. Hence the guarantee has the same function as collateral - it increases the costs $A$ must bear at a loss and thus the level of care taken by $A$.

Another reason why a guarantee may increase the value of the project is that $G$ may have information about $A$ that $B$ does not have. We assume asymmetric information in that $A$ but not $B$ knows $p(\cdot)$ and the value of $x$. It is conceivable, however, that some third party knows $x$ and $p(\cdot)$. The third party may be a business partner, a relative, or a bank that knows $A$ relatively well and has information about $A$ 's business. Assume that $G$ is this third party. $G$ knows $p(\cdot)$ and observes $x$. Assume also that $G$ is able to price marginal changes in the control taken by $A$. In particular, assume that the price of the guarantee, $I$, is a function of $x$ such that

$$
I_{x}=p_{x} L .
$$

In this case, the guarantee will steer $A$ 's choice of care to $x$. This is possible even if $G$ cannot collect anything from $A$ ex post at a loss. To see this, assume that $M^{G}=0$. The net values to the three parties are in this case

${ }^{9}$ An alternative form also observed in practice is for $G$ to agree to pay the difference $L-M^{G}$ to $B$, while $A$ remains liable to $B$.

${ }^{10} B$ may also pay for the guarantee. This would not materially change the analysis, bccause $B$ can be compensated via $R$ without changing any incentives. 


$$
\begin{aligned}
& N V^{A}=R-w x-I(x), \\
& N V^{B}=Y-R, \\
& N V^{G}=I(x)-p(x) L .
\end{aligned}
$$

A's care satisfies

$$
w=-I_{x},
$$

which is optimal given the price schedule (7). Thus we see that the requirement and acceptance of a guarantee issued by $G$ may be a beneficial agreement even in situations where $G$ cannot collect anything from the liable party. The increased value of the project due to the guarantee can be shared between $A, B$ and $G$ in a mutually beneficial way by the choice of $R$ and $I$.

In sum, a guarantee may increase the value of a project if $G$ has a comparative advantage in claims collection or specific information that enables $G$ to influence the care taken. A guarantee also can be seen as an alternative to repeated dealings - repeated dealings do not solve the credibility problem if the expected value of continued trade remains small relative to the claim at a loss.

Note that the argument for a guarantee is similar to the argument for vicarious liability in tort-law (Sykes, 1984, and Shavell, 1986). That is, a "judgement-proof" problem arises when a party that has been found legally liable is unable to pay fully the claim. Someone else - for instance, an employer - may then be held vicariously liable. This can be efficiencyincreasing because the employer observes the employee continuously and has power to reward or to dismiss the employee. ${ }^{11}$

\subsection{Insurance}

An insurance contract is very close to a guarantee. In fact, the guarantee above is equivalent to an insurance contract in which $A$ pays a premium of $I$ and the insurer compensates losses in excess of a deductible of size $M^{G}$. To increase the value of the project, the insurer must have a comparative advantage in collecting claims and/or must have some information on $p(\cdot) L$. Insurers also gather information on the expected loss and on the control taken. In a perfect world in which the insurer knows the marginal impact of the control, the insurer can steer $A$ 's behavior to $x^{\prime \prime}$ by conditions in the policy and by varying premiums (Shavell 1979).

The demand for a transfer of the risk to an external guarantor/insurer arises because the potential loss is large and because the insurer/guarantor has a comparative advantage in obtaining information about the risky project and about the party that directly controls the value of the project. Risk-aversion does not change this result.

To see this, assume that $A$ is risk-averse while $B$ and $G$ are either risk-neutral or able to diversify risks completely. Under zero transactions costs when both $A$ and $B$ are fully informed of the shape of $p(\cdot) L$, they contract, as in section 3.2., on $x^{*}$. The potential loss due to $A$ 's risk-aversion can then be eliminated simply by making $B$ liable for the potential loss $\left(s^{A}=0\right.$ and $\left.s^{B}=1\right)$.

11 Parents are for the same reason often liable for damages caused by their children. Similarly, professional associations and branch organizations with the power to exclude and control members may be willing to guarantee the service of their members (Skogh, 1989b). Such transfers of risks to third parties that may influence the behavior of the liable party are common. 
Under asymmetric information when no guarantor/insurer is available (section 3.3.), there is a trade-off between the amount of risk borne by $A$ and the increase in the value of the project due to increased liability borne by $A$. The liability will therefore be shared between $A$ and $B$ and the control will differ from $x$.

When the risk can be transfered to $G$, the potential loss from $A$ 's risk-aversion can be eliminated by full coverage $\left(M^{G}=0\right)$. The net values $N V^{A}, N V^{B}$ and $N V^{G}$ are then given by (1"'), (2") and (6'), respectively. The control taken by $A$ may again be steered to $x$. In this case, the guarantee/insurance has the joint benefit of increasing the value of the project and eliminating the disutility due to risk bearing by the risk-averse agent $A$.

\section{Specialization in certain risks and customers}

\subsection{Many risks and periods}

We now argue that the differences between financial intermediaries are due to their specialization in specific risks and customers. To see this, we first extend the analysis to situations with more than one risk.

Most real projects include many risks and many controls that influence the expected value of a project. The net present value of such a project may be written

$$
\mathrm{NPV}=\sum_{t=0}^{T} \sum_{i=1}^{N} p_{i t}\left(x_{1 t} \ldots x_{m t}\right) C_{i t} /(1+r)^{t}
$$

where $p_{i t}$ denotes the probability of state $i$ in period $t$. In (3'), $\Sigma p_{i t}=l$ for all $t$, and there are $m$ controls that influence these probabilities in each period. Also, $C_{i t}$ is the cash-flow in state $i$ in period $t$, and $r$ is the discount rate. ${ }^{12}$

The presence of a large number of risks, controls, and periods does not materially change the results. In a world without transactions costs, and with information on $p(\cdot)$, parties $A$ and $B$ contract on all controls as in the one-period case in section 3.1., and the outcome is efficient.

Under asymmetric information, it is possible to establish an efficient contingent claim contract by adjusting the distribution of liabilities. If $A$ determines all controls, it is efficient to make $A$ liable for all losses. ${ }^{13} A$ would then become the residual claimant in accordance with Alchian and Demsetz's (1972) theory of the firm.

However, there are often large potential losses that the entrepreneur is not able to cover. Collateral such as mortgages may therefore be required. External risk-carriers like guarantors may also be required.

12 This representation of the net present value differs from the traditional textbook case in corporate finance, which assumes that the expected cash-flows of a project are not influenced by controls, or by the liability of the asset-holders.

${ }_{13}$ If several agents take the controls, and one agent cannot efficiently be vicariously liable for all others, an efficient liability rule requires information about optimal levels of care of all agents with controls. 


\subsection{Creditors and equity-holders}

A creditor that covers insolvency risks must be credible. There must be no doubt that the guarantor has sufficient funds to indemnify the loss, and the parties must trust that the guarantor will fulfill commitments. Also, the guarantor must be relatively well informed about the risk in question and/or have a comparative advantage in the collection of claims. This helps explain why banks often act as guarantors. Banks usually have sufficient funds to cover losses, and banks may be able to diversify risks by choices of portfolios. As a creditor, a bank can collect from the debtor to the limit set by bankruptcy. The creditor is also a residual claimant if the debtor becomes insolvent and thus the creditor has an incentive to gather and use information to steer the debtor's activitites. The behavior of the debtor may bc influenced, for instance by varying interest rates and amortization schedules. The bank may also require that the customer's books be audited and that the bank be represented on the board of the debtor's firm.

The information collected by the guarantor appears to be transaction-specific. The issuing of guarantees is therefore primarily a small-scale business. The guarantor may be a local bank, an employer, a relative, or some other party with specific local or personal information about the debtor and also with some power to collect claims. This may partly explain why banks often specialize in dealing with specific customers such as households, farmers, or branches of industries.

Note that the equity of a firm has roughly the same function as a guarantee. If $A$ is an entrepreneur with limited assets and hence liability, the value of a project may increase if equity is added, as in Leland and Pyle (1977). If the entrepreneur adds equity, this equity functions like collateral. If external stock-holders add to equity, they act as guarantors of the liabilities of the entrepreneur. ${ }^{14}$ To increase the value of the firm, the external equityholders typically demand influence over the behavior of the entrepreneur, as is done through voting rights and through operations in the stock market (Jensen and Meckling, 1976).

\subsection{Property and liability insurance}

Let us now compare the banking industry with the property and liability insurance industry. The industries differ in important respects even though both industries provide financial intermediation. Banks specialize the various business risks that are usually not insured by property and liability insurance firms. Moreover, while the comparative advantage in bearing credit risks appears to be due to specific (small-scale) information on customers and their businesses, property and liability insurers appear to utilize economies of scale by specializing in a specific risks such as fire, storm, traffic accidents, and third party liability.

A characteristic of such risks is that there are a large number of low probability lossevents. The traders and/or guarantors in a given commercial business usually have little detailed information on such risks. The existence of a separate property and liability insurance industry appears to be partly duc to cconomies of scale in the gathering of information on such low probability events. By insuring a large number of similar projects, the insurer obtains information on the actuarial relation betwecn damages, the presence of safety

14 The liability of stock-holders in corporation is obviously limited to the value of equity. 
devices, levels of dcductibles, and costs of various claim settlement procedures. To capture most of the value from gathering actuarial information, it is helpful to keep the information secret and/or to have a large market share. The insurer also needs to be large enough to diversify the risks it holds. The sizc of the immediatc pool is not decisive, however, when re-insurance is available.

Accident risks involving water, storm, traffic, and firc have much in common, and claims-adjustment proccdures for them are similar. The common features and similarities in claims adjustment are an important source of economics of scalc. It is thus not surprising that these risks are often insured by the same insurer. It is often advantageous to transact a whole bundle of contingencies to the insurcr by the purchase of a single property and liability policy, because this reduces contracting costs.

The reliability problem also appears to help explain why insurcrs accept such risks and thus act as intermediarics. For instance, assume that a risk-management expert sells information directly to $A$ and $B$ on how to draw up a contract. The reliability of information provided by the risk-management expert may be low because of the low probability of cach event, which makes it difficult to assess the information. The risk-managcr may thereforc signal quality by accepting the risk. This might involve payment to the risk-manager of an ex ante premium that covers expected claims, but such a contract is in cssence an insurance contract.

A risk-manager who does not want to become a residual claimant must signal reliability in some other way. One possibility may be to sell information repeatedly to a limited number of customers such as to large firms with a relatively large number of similar accidents, or to insurers that are able to judge the quality of the information.

\subsection{Trade-credit insurance}

It is also of interest to compare guarantors and trade-credit insurers. ${ }^{15}$ Both cover credit risks but the two industries differ considerably. The trade-credit industry is organized on a large scale, often with only a few firms in each country, while many guarantors are smaller firms or are individuals. Moreover, trade-credit insurers typically insure all of a firm's customer-claims, while the guarantor selects specific credit risks to cover. Here we provide a tentative explanation of these differences.

In most manufacturing industries, payment is made some time after delivery with a credit length varying from several weeks to a year or more. Faith and Tollison (1981) argue that post-payment is a rational choice designed to control a principal-agent problem. Especially for "experience goods" (Shapiro, 1983), quality cannot bc identified until after the use of the product. ${ }^{16}$ With post-payment, an unsatisfied buyer may return the good or withhold payment. From the seller's point of view, post-payment serves as a signal of quality.

15 Factoring is nearly the same as trade-credit insurance, if defaulted claims arc not recoursed to the creditor. Such non-recourse factoring is relatively frequent in the US (Mian and Smith, 1989).

16 There are other possible explanations for post-payments. One is that transactions costs are reduced by making fewer payments. Another is that there are costs of borrowing. The presence of positive interest only explains a fraction of the difference in prices between early and late payment in most cases, however. A third possibility is that there is a demand for credit in excess of that supplied by banks and other specialized creditors. This explanation makes the strong assumption that traders specialized in their own business also have a comparative advantage in financial intermediation. For a fuller discussion of some of these issues, sce Mian and Smith (1989). 
Post-payment results, however, in a secondary informational asymmetry due to the buyer's limited assets or limited willingness to pay. If the selling firm is unable to separate good and bad risks and thus charges the same (average) risk premium for all post-payments, the firm may end up with losses. The selling firm may in principle collect information to ferret out such bad risks. However, many selling firms are specialized in other activities and have limited experience with credit-risk assessments. One way such a firm can reduce the credit risk it bears is to stick to well-known customers, but this is obviously costly also. Credible guarantors that are willing to cover risks at reasonable costs might not be available, especially if; (i) claims are relatively small; (ii) there are many customers; and/or (iii) customers are unknown, which may be the case, for instance, with exports.

There is also a claims-collection problem that may result in a demand for external services. Traders' contracts are often unspecified or implicit about details. This may not cause serious problems in repeated exchanges. However, exchanges may cease to be repeated at bankruptcy, which may result in conflicts about the interpretation and enforcement of the obligations of the buyer. There may also be disputes with other claimants about remaining assets, which can delay settlement of bankruptcies. Firms may reduce both of these costs by selling claims to collection agencies.

Exposure to trade-credit risk may also induce a desire to pool. Pooling may be simple if the selling firm is a publicly traded corporation with diffuse ownership; owners can then merely adjust their portfolios. The same is true if the portfolio of claims of customers consists of many relatively small and independent claims. Pooling may be difficult, however, if customer claims are large and/or dependent. Small firms with large customer claims and firms with risk-averse owners (or employees) who are unable to diversify risks may therefore demand external pooling.

Economies stem from the public-good nature of information. The insolvency risk of one firm is of interest to all of its creditors, so a large insurance firm insuring several creditors of each debtor/buyer will receive a greater return to information on a debtor than would a small insurer. Such information may be purchased by the trade-credit insurer from local guarantors with specific information about debtors. There are similar economies in claims collection - a large insurer may collect claims from several policies at the same bankruptcy.

Another source of economies is from possible adverse selection by the insured. That is, the seller may have information about the insolvency risks of its customers that is not available to the insurer. It may therefore be profitable for the seller to insure only bad risks. To reduce this adverse selection, insurers typically require that the seller not exclude any part of its trade-credit portfolio from insurance (Karrer, 1957). (The insurer may, however, exclude some risks from insurance coverage.)

The different sources of economies and the benefits of joint production of pooling, risk-assessment, and claims-collection appear to explain the concentration and specialization in the trade-credit-insurance industry. In many countries, only one or a few large tradecredit insurers exists (Briggs \& Edwards, 1988). Internationally, trade-credit insurers cooperate via the International Credit Insurance Association. They exchange credit information, they cooperate in claims collection services, and they reinsure.

The trade-credit-insurance industry covers credit risks only, which is in contrast to property and liability firms that supply policies that cover a variety of accident risks. Karrer 
(1957) explains this by the specific nature of credit risks as compared with accident risks. However, within the credit risk business there are no sharp borders. Trade-credit insurers often act also as guarantors of various industrial projects, here in compctition with banks. Some trade-credit insurers also sell credit information and claims collection services separately. ${ }^{17}$

\section{Concluding remarks}

We have shown how collateral, guarantees, and insurance may increase the value of economic activities. They do this by increasing the care taken by a party that cannot be made fully liable. Guarantors/insurers specialize in gathering information on specific risks and customers. A demand for such external risk-carriers can exist even if the liable party (the insured) is risk-neutral. Given risk-aversion, the guarantee/insurance has the joint benefit of increasing care and eliminating the disutility due to risk-aversion.

Contracting usually involves a large number of contingencies. Contracting costs are reduced and the value of a project increascd by transfering risks to external parties with a comparative advantage in carrying risks. Tentative evidence supports this view. Contracts often include clauses requiring collaterals, guarantees, and insurance of various risks. For instance, when a house-owner or an entrepreneur borrows funds, the bank usually requires that the loan is secured by a mortgage. A personal guarantee issued by relatives or friends may also required, as well as property and liability insurance. The credit risk covered by the bank is thereby reduced to a limited number of large potential losses that cannot be transfered to somebody else at relatively low costs.

It also seems clear that financial intermediaries differ in the risks and customers in which they specialize. Guarantors often have long-term relations with their customers. The person-specific or transaction-specific information held by guarantors cannot easily be traded, which may explain why guarantors typically operate on a small scale. In most countries, banks specialize in local customers and branches of industries. The property and liability insurance industry specializes, on the other hand, in accident risks. Economies of scale in the gathering of information on the low-probability events insured by propertyliability firms partly explains the relative large scale of such firms. The trade-credit insurance industry is also primarily a large-scale business. It is specialized in the insurance of whole portfolios of trade-credits. Typically, debtors (buyers) are relatively unknown to creditors (sellers). The trade-credit insurer utilizes economies in the gathering of general credit-risk information on a large number of debtors.

17 Separate rating bureaus, risk-managcrs, and claims collectors scll information on credit risks, partly in competition with insurers, and partly with insurers as customers. Journals publish easycollected information. A reason why there is a market for such publicly accessible information may be that firms can sort, present, and interpret public information in a way that is valuable to specific readers or customers. In the US, there are large rating bureaus with well established reputations. The explanation may be that separate functions like risk-assessment, lending, collection, and risk-bearing can be separated by a specialized firm, and that a rcputation may be established without being an intcrmediary. 


\section{REFFRFNCFS}

AKERLOF, G. (1970), "The Market for 'Lemons: Qualitative uncertainty and the market mechanism", Quarterly Journal of Economics, Vol. 84, pp. 488-500.

ALCHIAN, A. A. and DFMSFTZ, H. (1972), Production, Information Costs, and Fconomic Organization. American Economic Review, 62 (December): pp. 777-795.

BFNSTON, G.J. and SMITH, C.W., Jr. (1976), A Transactions Cost Approach to the Theory of Financial Intermediation. Journal of Finance, Vol. 31, No. 2, pp. 215-231.

BENSTON, G. J., HANWECK, G. A. and HUMPHREY, D. B. (1982), Scale Fconomics in Banking: A Restructuring and Reassessment. Journal of Money, Credit and Banking, 14:4, pp. 435-456.

BRIGGS, D. and EDWARDS, B. (1988), Credit Insurance. How to reduce the risks of trade credit. Woodhead-Faulkner.

DIAMOND, D. W. (1984), "Financial Intermediation and Delegated Monitoring", Review of Economic Studies, Vol. LI, pp. 393-414.

DIAMOND, D.W. and DYBVIG, P. H. (1986), Banking Theory, Deposit Insurance and Bank Regulation. Journal of Business, Vol. 59, No. 1, pp. 55-68.

FAITH, R.L. and TOLLISON, R. D. (1981), "Contractual Exchange and the Timing of Payment", Journal of Economic Behaviour and Organization, Vol. 1, pp. 325-342.

FAMA, E. F. (1990), Contract Costs and Financing Decision. Journal of Business. No. 1:2, pp. S75-S91.

GOLDBERG, V. (1988), Accountable Accountants: Are Third-Party Liability Necessary? The Journal of Legal Studies, Vol. 17, pp. 295-311.

JENSEN, M.C. and MECKLING, W. H. (1976), Theory of the Firm: Manageral Behaviour, Agency Costs and Ownership Structure. Journal of Financial Economics, No. 3, pp. 305-360.

KARRER, H. (1957), Elements of Credit Insurance. An International Survey. Sir Isaac Pitman \& Sons, Ltd, London.

LELAND, H. and PYLE, D. (1977), "Informational Asymmetries, Financial Structure, and Financial Intermediation", Journal of Finance, Vol. 32, pp. 371-387.

MAIN, B. G. (1982), "Business Insurance and Large, Widely-heId Corporations", Geneva Papers on Risk and Insurance, pp. 237-247.

MAIN, B. G. (1983), "Why Large Corporations Purchase Property/Liability Insurance", California Management Review. Vol. XXV, No. 2, pp. 84-95.

MAYERS, D. and SMITH, Jr., C. W. (1981), "Contractual Provisions, Organizational Structure, and Conflict Control in Insurance Markets", Journal of Business, Vol. 54, No. 3, pp. 407-434.

MAYERS, D. and SMITH, Jr., C. W. (1982), "On the Corporate Demand for Insurance", Journal of Business, Vol. 55, No. 2, pp. 28I-295.

MAYERS, D. and SMITH, Jr., C.W. (1987), "Corporate Insurance and the Underinvestment Problem" Journal of Risk and Irtsurance, No. 1, pp. 45-54.

MIAN, S.L. and SMITH, C. Jr. (1989), Accounts Receivable Management Policy: Theory and Evidence. The University of Rochester. Workingpaper No. MERC 88-02.

MODIGLiANI, F. and MILlER, M. (1958), The Costs of Capital, Corporation Finance and the Theory of Investment. American Economic Review, 48:333-91.

SHAPIRO, C. (1983), "Optimal Pricing of Experience Goods", Bell Journal of Economics, No. 14, pp. 497-507. 
SHAVELL, S. (1979), On Moral Hazard and Insurance. Quarterly Journal of Economics, No. 93, 541562.

SHAVELL, S. (1986), The Judgement Proof Problem. International Review of Law and Economics, pp. 45-58.

SHAVELL, S. (1987), An Economic Analysis of Tort Law. Harvard University Press.

SKOGH, G. (1989a), "The Transactions Costs of Insurance: Contracting Impediments and Costs", Journal of Risk and Insurance, pp. 726-732.

SKOGH, G. (1989b), Professional Liability Insurance in Scandinavia. The Liability of Accountants, Barristers and Estate Agents", Geneva Papers on Risk and Insurance, pp. 360-370.

SMITH, Jr., C. W. and WARNER, J. B. (1979), "On Financial Contracting. An Analysis of Bond Covenants", Journal of Financial Economics, pp. 117-161.

SPENCE, M. A. (1974), Market Signaling: Informational Transfer in Hiring and Related Screening Processes, Harvard University Press, Cambridge, Mass.

STIGLITZ, J. E. and WEISS, A. (1981), "Credit Rationing in Markets with Imperfect Information", American Economic Review, Vol. 71, No. 3, pp. 393-410.

SYKES, A. O. (1984), The Economics of Vicarious Liability. Yale Law Journal. Vol. 93: 1197, pp. 1231-1280.

WILLIAMSON, O.E. (1979), Transaction-Cost Economics: The Governance of Contractual Relations. Journal of Law and Economics, 22 (Oct.), pp. 13-61. 